\title{
Scintillators based on zinc selenide and ticor for detection of charged particles
}

\author{
V.D.Ryzhikov, E.A.Danshin, N.G.Starzhinski, E.A.Losseva, V.V.Chernikov \\ Scientific and Technological Center for Radiation Instruments, Concern "Institute for Single Crystals" of NAS of Ukraine \\ 60 Lenin ave., Kharkov, 310001, Ukraine \\ Phone: 380(572) 321 379; Fax:380(572) 321391; E-mail: root@stcri.kharkov.ua
}

\section{L.A.Litvinov}

Department of optical and constructional crystals, Concern "Institute for Single Crystals" of NAS of Ukraine 60 Lenin ave., Kharkov, 310001, Ukraine

Phone: 380(572)328230; Fax: 380(572)320019; E-mail: occd@isc.kharkov.com

\begin{abstract}
Studies of charged particle detectors based on $\mathrm{ZnSe}(\mathrm{Te})$ and $\mathrm{Al}_{2} \mathrm{O}_{3}\left(\mathrm{Ti}^{+3}\right)$ (ticor) optically connected with photodiodes (PD) of S3590 type are reported. The charge-sensitive preamplifier connected with PD had equivalent noise level of 420 electrons with formation time of $5 \mu \mathrm{s}$.

The signal value from ticor on ${ }^{207} \mathrm{Bi}$ internal conversion electrons (ICE) with $E_{e}=976 \mathrm{keV}$ is equivalent to the signal value from $E_{\gamma}=14 \mathrm{keV}$ when PD operates in the semiconductor detector mode (without a scintillator); from a-particles with $E_{\alpha}=5150 \mathrm{keV}$ it corresponds to $20 \mathrm{keV}$. From these results, $\alpha / \beta$-ratio is $\sim 0.28$. Energy resolution of ticor on $\alpha$-particles $R_{\alpha}$ with $E_{e}=5150 \mathrm{keV}$ is $11.6 \%$, on ICE with $E_{e}=976 \mathrm{keV} R_{e 1 / 2}=15 \%$. Under the same conditions $R_{\alpha}=3 \%$ and $R_{e}=3.7 \%$ for single crystal $\mathrm{ZnSe}(\mathrm{Te})$. A possibility to create combined detectors of electrons and $\alpha$-particles on the basis of these two scintillators is discussed.
\end{abstract}

Keywords: zinc selenide, ticor, spectrometry, charged particle.

Paper received 09.10.99; revised manuscript received 24.12.99; accepted for publication 14.03.00.

\section{Introduction}

Scintillation crystals $\mathrm{ZnSe}(\mathrm{Te})$ are widely used in detectors for radiometric and dosimetric instruments, in radiation introscopes and other systems of radiation monitoring [1-3]. Recently, studies have been carried out on a possibility to use $\mathrm{ZnSe}(\mathrm{Te})$ crystals for detection of light and heavy charged particles, in dispersion detectors of thermal and fast neutrons [4, 5]. Principal advantages of $\mathrm{ZnSe}(\mathrm{Te})$ crystals over oxide and alkali halide scintillators are their high thermal and radiation stability, high conversion efficiency as well as good matching of the emission spectrum and sensitivity maximum of silicon photodiodes.

Crystals $\mathrm{Al}_{2} \mathrm{O}_{3}\left(\mathrm{Ti}^{+3}\right)$ (ticor) are used mostly in quantum electronics. The first results on their application for dosimetry of powerful fluxes of ionizing radiation have been presented in $[6,7]$. High chemical stability and thermal stability of output parameters allows to use these crystals for inspection of liquid radioactive wastes or fuelcontaining masses. Relatively low effective atomic number $Z_{\text {eff }}$ and small radiation capture cross-section of thermal neutrons $\sigma_{n, \gamma}$ allow to think of ticor crystals as promising materials for measurement of $\beta$-particle fluxes in thermal neutron fields.

The aim of the present work was to study spectrometric characteristics of $\mathrm{ZnSe}(\mathrm{Te})$ and ticor crystals in the course of $\alpha-, \beta$-, $\gamma$-radiation detection in the broad energy range, as well as to determine $\alpha / \beta$-ratio for detectors based on these crystals and designed for simultaneous and separate detection of charged particles and radiations of different types.

\section{Experimental}

For the experiments we chose single crystals grown as described in [8]. From the single crystals, plates were made with dimensions $10 \times 10 \mathrm{~mm}^{2}$ and $1-8 \mathrm{~mm}$ thickness. 


\section{V.D.Ryzhikov et al.: Scintillators based on zinc selenide and ticor...}

The output windows of the plates (directed towards the photosensitive surface of the photodiode) were mated, and the input windows (those directed towards the charged particle flux) were polished. The plates were packed into teflon containers with collimator windows on input windows for transmission of charged particles. The output characteristics of crystals $\mathrm{ZnSe}(\mathrm{Te})$ and $\mathrm{Al}_{2} \mathrm{O}_{3}\left(\mathrm{Ti}^{+3}\right)$ are presented in Table 1 ( $\lambda_{\max }$ is luminescence maximum, $\tau$ decay time, $\alpha$ - absorption coefficient, $Z_{\text {eff }}-$ atomic number, $S$ - relative light output, $T_{\max }-$ maximum operation temperature).

Table 1. Characteristics of scintillators produced in Concern «Institute for Single Crystals»

\begin{tabular}{lllllll}
\hline Crystal & \multicolumn{2}{l}{$\lambda_{\text {max }}, \mathrm{nm} \tau, \mu \mathrm{s}$} & $\alpha, \mathrm{cm}^{-1}$ & \multicolumn{2}{l}{$Z_{\text {eff }} S$, rel.un. $T_{\text {max }}, \mathrm{K}$} \\
\hline $\mathrm{ZnSe}(\mathrm{Te})$ & $600-620$ & $2-20$ & $0.05-0.15$ & 33 & 100 & $400-450$ \\
& $630-640$ & $>20$ & & & 170 & \\
$\mathrm{Al}_{2} \mathrm{O}_{3}(\mathrm{Ti})$ & 750 & $3-4$ & - & 12 & $16-20$ & 350 \\
$\mathrm{CsI}(\mathrm{Tl})$ & 550 & $0.63-1$ & $>0.05$ & 54 & 100 & $350-400$ \\
\hline \hline
\end{tabular}

Spectrometric parameters of crystals were studied using sources of internal conversion electrons ${ }^{109} \mathrm{Cd},{ }^{137} \mathrm{Cs}$, ${ }^{207} \mathrm{Bi}$, source of $\alpha$-particles ${ }^{239} \mathrm{Pu}$, as well as sources of $\mathrm{X}$ ray and $\gamma$-quanta of ${ }^{55} \mathrm{Fe},{ }^{241} \mathrm{Am},{ }^{57} \mathrm{Co},{ }^{137} \mathrm{Cs},{ }^{22} \mathrm{Na}$ at $\mathrm{T}=294 \mathrm{~K}$. Photodiodes of S3590-01 type (Hamamatsu, Japan) and "Porog" type photodiodes produced by NCB "Ritm", Chernovtsy, Ukraine, were used. Their comparative characteristics are shown in Table 2.

Table 2. Parameters of Si photodiodes

\begin{tabular}{lll}
\hline \hline Parameters & S3590-01 & «Porog» \\
\hline Light sensitive area, $\mathrm{mm}^{2}$ & $10 \times 10$ & $10 \times 10$ \\
Dark current, $\mathrm{nA}$ & 30 & 30 \\
Capacitance, $\mathrm{pF}$ & 70 & 67 \\
Sensitivity for $\lambda=540 \mathrm{~nm}, \mathrm{~A} / \mathrm{W}$ & 0.31 & 0.26 \\
\hline \hline
\end{tabular}

Spectral sensitivity maximum of Si-PIN-PD is in the $800-900 \mathrm{~nm}$ range, which matches by $70 \%$ the radioluminescence spectrum of crystals $\mathrm{ZnSe}(\mathrm{Te})$. High requirements were put to all parts of the spectrometric circuit, especially to the charge-sensitive preamplifier (CSPA). CSPA comprises a charge sensitive section with a field transistor at the input and power supply elements of the photodiode. Our studies have shown that the lowest level of intrinsic noise can be obtained with KP 341A field transistors (calculated noise level $<400 \mathrm{e}$ at Si-PIN-PD capacitance of $70 \mathrm{pF}$ ). After the preamplifier, further amplification and shaping was made by an active filter-amplifier of 1101 type with additionally introduced shaping times to $40 \mu \mathrm{s}$. Studies of scintillation characteristics of single crystals $\mathrm{ZnSe}(\mathrm{Te})$ and ticor were carried out with shaping times $\tau_{1}$ $=15 \mu \mathrm{s}$ and $\tau_{2}=4 \mu \mathrm{s}$, respectively; studies of spectrometric characteristics of Si-PIN-PD as semiconductor detector of ionizing radiation - at $\tau_{3}=0.1 \mu \mathrm{s}$.

Spectrometric studies were carried out using multichannel analyzers based on Pentium Notebook PC and an original analog to digit converter (ADC) developed by STC RI and an original software. ADC is placed in the computer compartment intended for PCMCIA cards, has low energy consumption and power supply $+5 \mathrm{~V}$ from the computer wire. This arrangement makes the instrument small-sized.

\section{Results and discussion}

Pulse amplitude spectra measured by scintielectronic detectors with the studied crystals and Si-PIN-PD were measured on the amplitude scale from $\gamma$-quanta using a semiconductor Si-PIN-PD detector (SCD). The noise level of SCD and CSPA allowed to clearly detect KX-quanta of ${ }^{55} \mathrm{Fe}$ (Fig.1). Analysis of the spectrum and calculation of the PD-CSPA system noise level shows that the intrinsic noise level of the system is 420 electrons.

Spectra of ${ }^{109} \mathrm{Cd},{ }^{137} \mathrm{Cs},{ }^{207} \mathrm{Bi}$ internal conversion electrons obtained using a $\mathrm{ZnSe}(\mathrm{Te})$-based detector $\left(9 \times 9 \times 1 \mathrm{~mm}^{3}\right)$ and a S3590 type Si-PIN-PD are presented in Fig. 2. Spectra of ${ }^{241} \mathrm{Am} \gamma$-quanta, ${ }^{90} \mathrm{Sr} \beta$-particles and ${ }^{239} \mathrm{Pu} \alpha$-particles obtained in the same way are shown in Fig. 3.

Energy resolution of the detector over $\alpha$-particles with $E_{\alpha}=5150 \mathrm{keV}$ is $R_{a}=3 \%$ (Fig. 3). The value of intrinsic resolution of crystal $\mathrm{ZnSe}(\mathrm{Te}) R_{a}$ was determined as

$$
R_{\alpha}=\sqrt{R_{d}^{2}-R_{p}^{2}}
$$

where $R_{d}$ is resolution of the detector-CSPA with $\alpha$-particles $(155 \mathrm{keV})$, and $R_{p}$ is resolution of the system detector capacitance-CSPA with pulse generator $(63 \mathrm{keV})$. Hence $R_{\alpha}=141.6 \mathrm{keV}$ or $R_{\alpha}=2.75 \%$, which is not worse than the best $\mathrm{CsI}(\mathrm{Tl})$ crystals measured with PMT.

Energy resolution of detectors of $\mathrm{ZnSe}(\mathrm{Te})$ - Si-PIN-

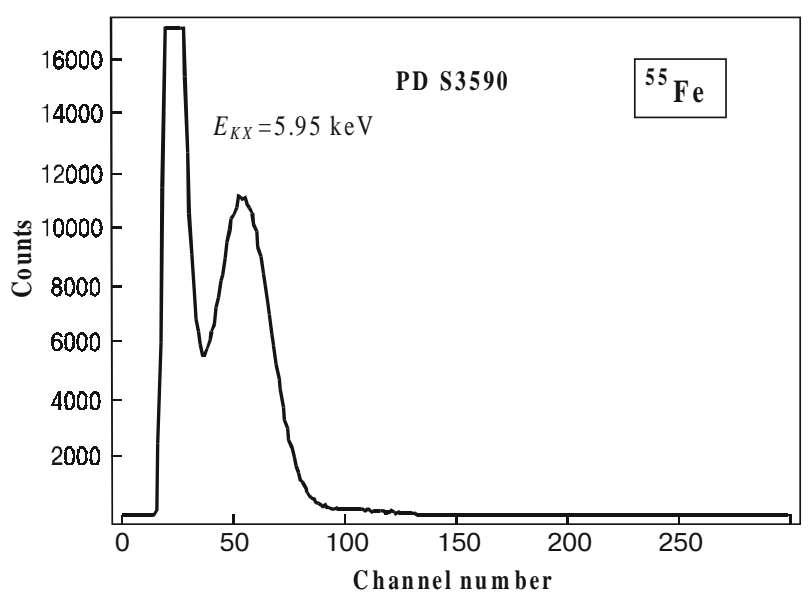

Fig. 1. Spectrum of ${ }^{55} \mathrm{Fe} \mathrm{KX}$-quanta obtained using a semiconductor detector based on S3590 type Si-PIN-PD. 


\section{V.D.Ryzhikov et al.: Scintillators based on zinc selenide and ticor...}
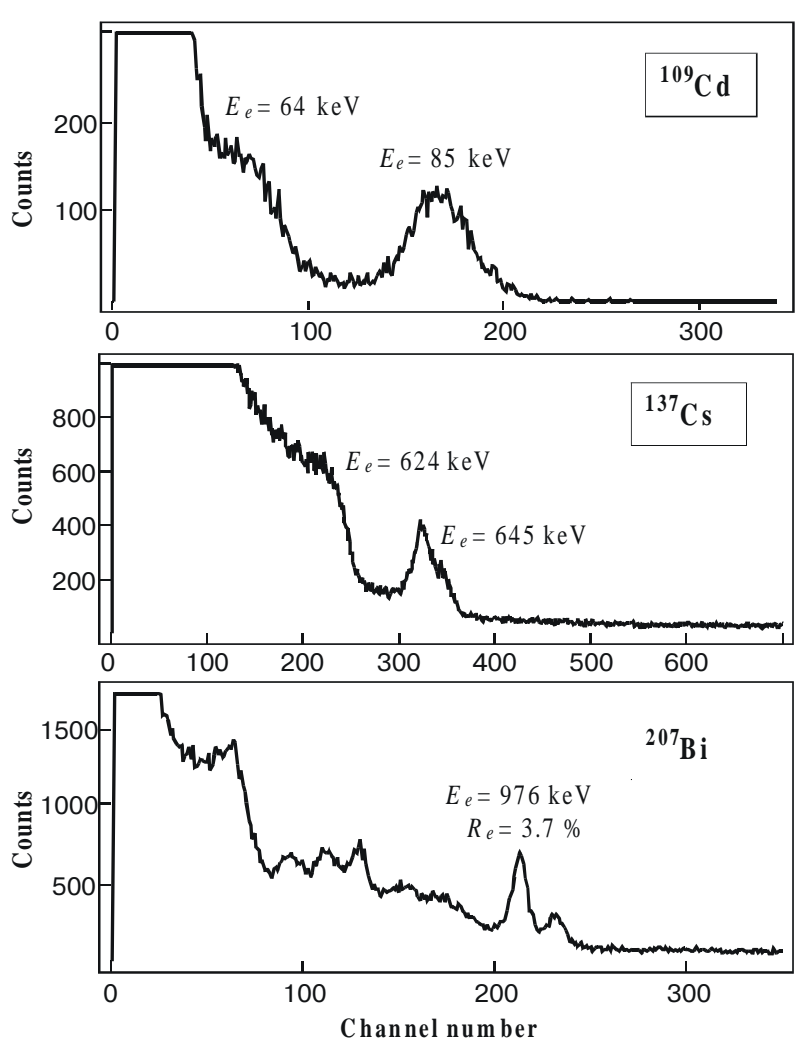

Fig. 2. Spectra of internal conversion electrons of ${ }^{109} \mathrm{Cd},{ }^{137} \mathrm{Cs}$, ${ }^{207} \mathrm{Bi}$ obtained using detector based on $9 \times 9 \times 1 \mathrm{~mm}^{3} \mathrm{ZnSe}(\mathrm{Te})$ crystal and S3590 type Si-PIN-PD.
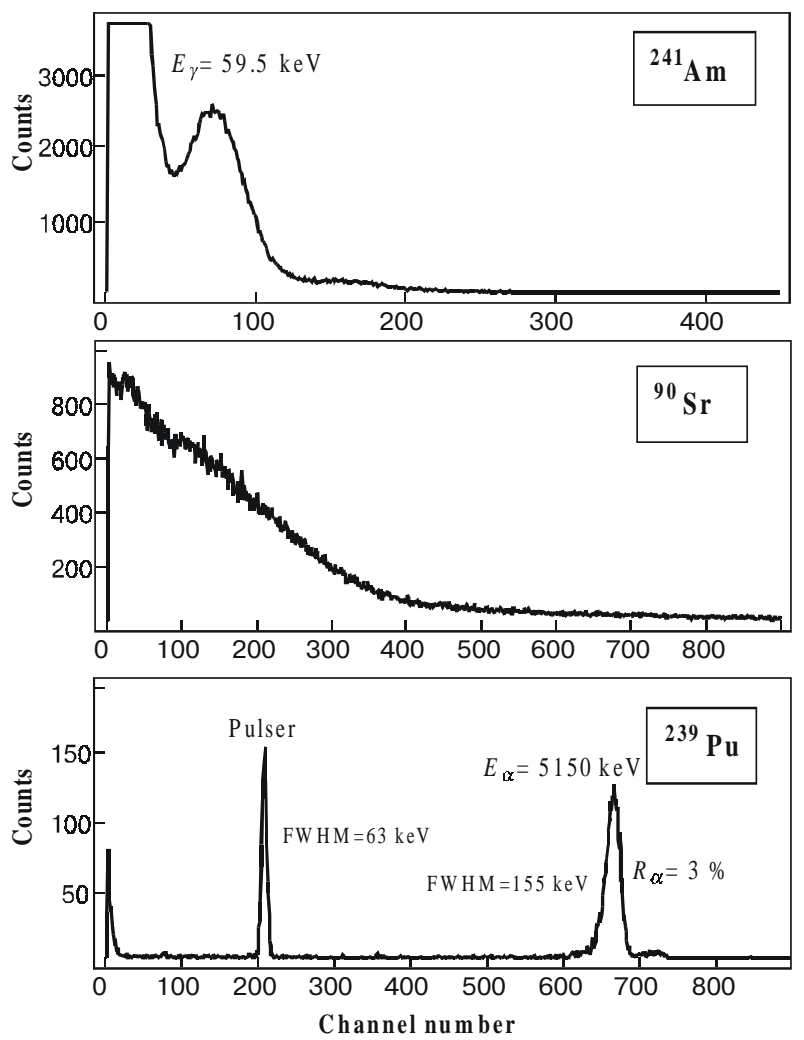

Fig. 3. Spectra of ${ }^{241} \mathrm{Am} \gamma$-quanta, ${ }^{90} \mathrm{Sr} \beta$-particles and ${ }^{239} \mathrm{Pu} \alpha$ particles obtained using detector based on $9 \times 9 \times 1 \mathrm{~mm}^{3} \mathrm{ZnSe}(\mathrm{Te})$ crystal and S3590 type Si-PIN-PD.
PD system with internal conversion electrons of ${ }^{207} \mathrm{Bi}$ $R=3.7 \%$. This is better than results obtained with best plastic scintillators with PMT $(5-7 \%), \alpha / \beta$-Ratio for $\mathrm{ZnSe}(\mathrm{Te})$ crystals is $\sim 1$, which is substantially higher than with alkali halide and oxide scintillators.

Studies of "fast" $\mathrm{ZnSe}(\mathrm{Te})$ crystals, which were also prepared at STC RI, have shown that energy resolution $R_{\gamma}$ of detectors of " $\mathrm{ZnSe}(\mathrm{Te})$ - avalanche photodiode" for $\gamma$-radiation with $E_{\gamma}=662 \mathrm{keV}$ is about $5.4 \%$; intrinsic resolution is $R_{\gamma}{ }^{*}=3.3 \%$ [8].

Spectra of ${ }^{207} \mathrm{Bi}$ internal conversion electrons, ${ }^{60} \mathrm{Co}$ $\gamma$-quanta and ${ }^{239} \mathrm{Pu} \alpha$-particles, obtained using detectors based on $\mathrm{Al}_{2} \mathrm{O}_{3}\left(\mathrm{Ti}^{+3}\right)$ and Si-PIN-PD (of S3590 type) are shown in Fig. 4. The value of energy resolution $R_{\alpha}=$ $11.6 \%$ with $\alpha$-particles $\left(E_{\alpha}=5150 \mathrm{keV}\right)$, with internal conversion electrons $\left(E_{e}=976 \mathrm{keV}\right) R_{e 1 / 2}=15 \%\left(R_{e 1 / 2}\right.$ value is measured over the right-hand side of the pulse amplitude distribution). Comparison with the signal from Si-PIN-SCD shows that the pulse amplitude from $E_{e}=$ $976 \mathrm{keV}$ with ticor is equivalent to the signal value with $E_{g}=14 \mathrm{keV}$ with Si-PIN-SCD, and from $\alpha$-particles of $E_{a}$ $=5150 \mathrm{keV}$ on ticor $-20 \mathrm{keV}$, respectively. $\alpha / \beta$-Ratio determined from these data was 0.28 , which corresponds to the values found with most oxide scintillators [9].

\section{Conclusions}
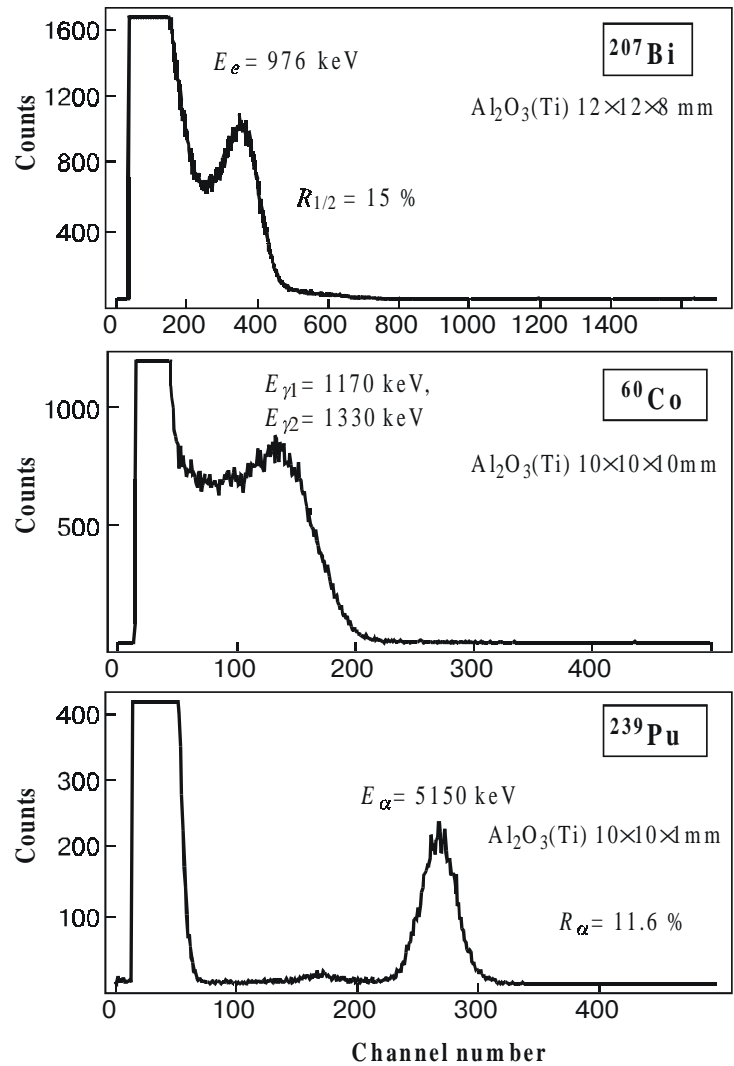

Fig. 4. Spectra of ${ }^{207} \mathrm{Bi}$ internal conversion electrons, ${ }^{60} \mathrm{Co} \gamma$ quanta and ${ }^{239} \mathrm{Pu} \alpha$-particles obtained using detector based on $\mathrm{Al}_{2} \mathrm{O}_{3}\left(\mathrm{Ti}^{3+}\right)$ and $\mathrm{S} 3590$ type Si-PIN-PD. 


\section{V.D.Ryzhikov et al.: Scintillators based on zinc selenide and ticor...}

Our studies of spectrometric characteristics of detectors based on Si-PIN-PD and crystals $\mathrm{ZnSe}(\mathrm{Te})$, as well as ticor, show that they are very promising for spectrometry of charged particles.

Basing on the results obtained on $a / b$-ratio, values of $R_{\alpha}, R_{e}, R_{\gamma}$, high thermal and radiation stability, we consider these crystals to be promising for applications in extreme conditions for detection and identification of decay products of radioactive materials of various origin.

\section{References}

1. V.Ryzhikov, V.Volkov, E.Danshin et al. Scintilectronic radiation detectors-solid-state detectors of new generation, preprint, Kharkov, p.66. (1995)

2. L.V.Atroschenko, S.F.Burachas, L.P.Gal'chinetskiy et al. Crystals of Scintillators and Detectors of Ionizing Radiations on their Basis, Naukova Dumka, Kyiv (1998)

3. V.Ryzhikov, V.Chernikov, L.Gal'chinetskii et al. The use of semiconductor scintillation crystals $\mathrm{A}^{\mathrm{II}} \mathrm{B}^{\mathrm{VI}}$ in radiation instruments // Journal of Crystal Growth, 199, pp.655-658. (1999).

4. V.D.Ryzhikov, V.G.Volkov, S.N.Galkin et al. Measurement and spectrometry of fluxes of charged particles using the scintillator-photodiode-preamplifier (S-PD-PA) system and new type scintillators based on the semiconductor $\mathrm{A}^{\mathrm{II}} \mathrm{B}^{\mathrm{VI}}$ compounds// International Conference on Optical Diagnostics of Materials and Devices for Opto-, Micro- and Quantum Electronics "OPTIM'97", Kiev, Ukraine, Abstracts, p.187 (1997)

5. V.D.Ryzhikov, Y.A.Borodenko, V.G.Volkov et al. Studies of dispersion detectors based on semiconductor compounds $\mathrm{A}^{\mathrm{II}} \mathrm{B}^{\mathrm{VI}}$ and transparent material with high neutrons trapping cross-section // Proc. of the International Conference on Inorganic Scintillators and their Application "SCINT 97", Shanghai, P.R. Chinf, pp.51-54. (1997)

6. J.A.Valbis, V.D.Ryzhikov, L.A.Litvinov et al. Single crystalline inorganic scintillator. Inventor's Certificate USSR No. 1410678 (1988).

7. E.V.Krivonosov, L.A.Litvinov, V.D.Ryzhikov. Scintillator based on $\mathrm{Al}_{2} \mathrm{O}_{3} / /$ Functional Materials, 4, No.4, p.602. (1997)

8. M.Balcerzyk, W.Klarma, M.Moszynski et al. Nonproportionality and temporal response of $\mathrm{ZnSe}(\mathrm{Te})$ scintillators studied by large area avalanche photodiodes and photomultipliers.// Scientific Program and Abstracts the Fifth International Conference on Inorganic Scintillators and Their Applications "SCINT 99”, P1-5, p.125, Moscow State University, Russia. (1999).

9. E.V.Sysoyeva, V.A.Tarasov, O.V.Zelenskaya et al. The study of $\alpha / \gamma$ ratio for inorganic scintillation detectors // Nuclear Instruments and Methods in Physics Research, A 414, pp. 274-278 (1998). 